\title{
Asma e rinite alérgica como expressão de uma única doença: um paradigma em construção
}

\author{
Asthma and allergic rhinitis as symptoms of the same disease: \\ a paradigm under construction
}

\author{
Paulo Augusto Moreira Camargos ${ }^{1}$, Mary Elisabeth Santos Moura Rodrigues ${ }^{2}$, Dirceu Solé ${ }^{3}$, Pierre Scheinmann ${ }^{4}$
}

\section{Resumo}

Objetivo: abordar os conceitos atuais sobre as inter-relações das vias aéreas superiores e inferiores e apresentar as evidências epidemiológicas, imunológicas e fisiopatológicas que respaldam o paradigma da entidade que se convencionou denominar de "doença das vias aéreas unidas".

Fontes dos dados: realizou-se levantamento bibliográfico, através de bancos de dados eletrônicos (Medline, MD Consult, HighWire, Medscape e LILACS) abrangendo os últimos 20 anos, utilizandose as palavras-chave asma e rinite alérgica.

Síntese dos dados: as evidências epidemiológicas das interrelações de rinite alérgica com asma incluem a prevalência de asma em pacientes com rinite alérgica e vice-versa, os resultados relatados pelo International Study of Asthma and Allergies in Childhood, a presença da hiper-responsividade brônquica em pacientes com rinite alérgica, bem como a importância dos fatores genéticos, ambientais e a idade de início da atopia como determinantes dessa associação. Aspectos morfológicos e fisiológicos também revelam as semelhanças e diferenças estruturais entre a mucosa nasal e brônquica, bem como os mecanismos que explicariam a influência da rinite alérgica na asma, especialmente a respiração oral secundária à obstrução nasal. Da mesma forma, evidências imunológicas revelam as conexões entre ambas, a saber, reações inflamatórias desencadeadas pela exposição aos alérgenos e a participação da medula óssea como provedora de precursores das células inflamatórias. Finalmente, são apresentados os resultados dos estudos sobre o efeito protetor do tratamento da rinite alérgica na redução da hiper-responsividade brônquica e no controle clínico e funcional da asma.

Conclusões: diante destas evidências é lícito admitir a rinite alérgica e a asma como doenças inter-relacionadas, e o paradigma da unicidade das vias aéreas abre perspectivas promissoras para o advento de estratégias terapêuticas integradas para estas afecções.

J Pediatr (Rio J) 2002; 78 (Supl.2): S123-S128: asma, rinite alérgica, epidemiologia, imunologia, patologia, tratamento.

\begin{abstract}
Objective: to describe current ideas about the relation between upper and lower respiratory tract and to review the epidemiological, immunological, and pathological aspects that support the paradigm of united airways disease.
\end{abstract}

Sources: literature review using the Medline, MD Consult, HighWire, Medscape and Lilacs databases. We used allergic rhinitis and asthma as keywords, and searched articles published in the past 20 years.

Summary of the findings: epidemiological evidence includes prevalence of allergic rhinitis in asthmatic patients and vice-versa, results of cross-sectional studies, bronchial hyperresponsiveness in patients with allergic rhinitis, importance of genetic and environmental factors, and the age of onset of atopic disease. Morphological and physiological aspects show structural differences between the nasal and bronchial mucosa, and the mechanisms that could explain the effect of rhinitis on asthma. Immunological aspects including the participation of bone marrow in the production of inflammatory cells and allergic reactions after allergen challenge are the same in allergic rhinitis and asthma. Finally, the results of the therapy for allergic rhinitis in bronchial hyperresponsiveness and in clinical and functional control of asthma are also reported.

Conclusions: epidemiological evidence and immunological and pathological aspects suggest that there is a relation between allergic rhinitis and asthma. The paradigm of united airways disease suggests the implementation of an integrated therapeutic approach.

J Pediatr (Rio J) 2002; 78 (Supl.2): S123-S128: asthma, allergic rhinitis, epidemiology, immunology, pathology, therapy.

1. Professor Adjunto, Doutor, Mestre em Medicina, Departamento de Pediatria, Disciplina de Pneumologia Pediátrica da Faculdade de Medicina da Universidade Federal de Minas Gerais (UFMG).

2. Professora Assistente, Mestre em Medicina, Departamento de Pediatria, Disciplina de Pneumologia Pediátrica da Faculdade de Medicina - UFMG.

3. Professor Titular Livre-docente - Departamento de Pediatria - Disciplina de Alergia, Imunologia Clínica e Reumatologia - Departamento de Pediatria da Universidade Federal de São Paulo - Escola Paulista de Medicina.

4. Professor Titular, Chefe do Service de Pneumologie et d'Allergologie Pédiatriques, Hôpital Necker-Enfants Malades, Paris. 
Desde há aproximadamente 50 anos, que a literatura registra observações empíricas das inter-relações existentes entre as vias aéreas superiores e inferiores, mas o conceito de unicidade das vias aéreas se tornou, especialmente nos últimos dez anos, um objeto específico de pesquisas experimentais e de alguns poucos estudos clínico-terapêuticos. Em pediatria, por exemplo, a experiência clínica constata, já há muito tempo, que crises de asma são precedidas e/ou desencadeadas por rinites, sejam elas de etiologia viral, como ocorre nos lactentes, sejam secundárias a estímulo alérgico nas crianças maiores. Todavia, a real importância da rinite, e até mesmo da sinusite que usualmente a acompanha, permaneceu relativamente subestimada, não tendo sido considerada, por exemplo, como comprometedora da qualidade de vida de pacientes asmáticos ${ }^{1}$.

One airway, one disease $e^{2}$, rinobronquite alérgica ${ }^{3}$, united airways disease $e^{3}$ e combined allergic rhinitis and asthma syndrome (CARAS) ${ }^{4}$ são expressões cunhadas mais recentemente, entre outros motivos, em função da elevação das taxas de prevalência e da interação existente entre rinite alérgica e asma. Estas entidades freqüentemente coexistem, sendo que a rinite é, atualmente, reconhecido fator de risco para desenvolvimento e agravamento da asma. A observação clínica cotidiana demonstra, com muita clareza, que o controle clínico e funcional de um paciente asmático com rinite alérgica associada não é satisfatório, se as manifestações das vias aéreas superiores não tiverem uma abordagem terapêutica adequada. $\mathrm{O}$ entendimento de que asma e rinite alérgica são manifestações de um mesmo processo inflamatório, substituindo a idéia de duas distintas entidades confinadas, cada uma delas, a um órgão específico, tem evoluído sobremaneira, e a literatura apresenta um robusto e atraente corpo de evidências que reforçam este novo paradigma, o que resultou, por exemplo, na elaboração de um documento publicado em colaboração com a Organização Mundial da Saúde, que recebeu a sigla "ARIA", construída a partir da fusão das primeiras letras da expressão inglesa Allergic Rhinitis and its Impact on Asthma ${ }^{1}$.

Esta revisão tem como objetivo apresentar aspectos epidemiológicos, morfológicos, fisiológicos, imunológicos, fisiopatológicos e as implicações terapêuticas destes conceitos.

\section{Evidências epidemiológicas}

Evidências epidemiológicas sugerem fortemente que os elos entre rinite alérgica e asma não são devidos ao acaso, sendo inúmeras as constatações desta co-morbidade ${ }^{5}$. A literatura dá conta de que 28 a $50 \%$ dos asmáticos têm rinite alérgica associada, enquanto que rinite alérgica isolada é encontrada em $20 \%$ da população geral. Por outro lado, asma coexiste em 13 a $38 \%$ dos pacientes com rinite alérgica, ao passo que na população geral esta proporção varia entre 5 e $15 \%$. Essas percentagens estão provavelmente subestimadas, já que em estudos mais recentes, usando questionários padronizados e validados, rinite foi relatada em $98,9 \%$ dos pacientes asmáticos com evidências de atopia, enquanto que esta proporção reduziu para 78,4\% entre asmáticos sem essas evidências ${ }^{3}$. Em média, $75 \%$ dos pacientes com asma acompanhada por marcadores de atopia têm rinite associada, e até $20 \%$ dos pacientes com rinite alérgica, muito particularmente aqueles com a forma perene ou persistente, padecem de asma de forma concomitan$\mathrm{te}^{3}$. Cifras semelhantes foram obtidas em levantamento realizado em ambulatório de pneumologia pediátrica no município de Belo Horizonte, que mostrou que entre 560 crianças e adolescentes com asma persistente, moderada ou grave, registradas no serviço e selecionadas aleatoriamente, no período 1996-2000, o diagnóstico de rinite alérgica foi firmado em 65\% delas (Profeta SC, Camargos PAM, dados não publicados).

Por outro lado, a presença de rinite em pacientes com asma tem sido confirmada como um marcador de gravidade para asma. Freqüência significantemente maior de relato de quatro crises ou mais de sibilância no último ano, distúrbio do sono por episódio agudo e broncoespasmo induzido por exercício foi observado entre escolares avaliados pelo questionário escrito do International Study of Asthma and Allergies in Childhood (ISAAC), e apresentavam as duas doenças associadas (Solé D, Camelo Nunes IC, Wandalsen $\mathrm{G}$, dados não publicados).

É amplamente reconhecido que a rinite alérgica perene (ou persistente, de acordo com a nomenclatura proposta pelo ARIA ${ }^{1}$ ) é acompanhada por algum grau de hiperresponsividade brônquica, sobretudo quando estão envolvidos fenômenos alérgicos relacionados com ácaros e pêlos de animais domésticos. Sabe-se, ademais, que durante a polinização, hiper-responsividade brônquica crescente mas transitória, com ou sem expressão clínica, é detectável em indivíduos suscetíveis. Parece provável que a rinite alérgica se constitua numa etapa prévia de uma "viagem em direção à alergia" e que, no amplo e complexo contexto da alergia, a rinite alérgica, com ou sem hiper-responsividade brônquica, e a asma possam se combinar e interagir de modo variável, segundo o indivíduo, a predisposição genética, a estação do ano, a exposição aos alérgenos e a idade ${ }^{1,6,7}$.

Bucca, ao avaliar pacientes não-asmáticos e com sintomas respiratórios, realizou broncoprovocação com histamina monitorada por curva fluxo-volume. Esses pacientes não eram asmáticos, ou haviam sido tratados por asma alguma vez na vida. A presença de hiper-responsividade brônquica foi documentada em $52 \%$ deles, e a de vias extratorácicas, em $71 \%$ deles, ocorrendo de modo simultâneo em $41 \%$. Segundo a autora, a disfunção de vias extratorácicas foi o principal fator relacionado aos sintomas respiratórios por eles apresentados ${ }^{8}$.

Assim, a análise dos fatores de risco e dos determinantes da associação entre as doenças de via aérea superior e via aérea inferior auxiliam na compreensão dos mecanismos envolvidos nesta associação, havendo demonstrações inequívocas de que a presença de atopia é o fator mais impor- 
tante para reforçar a inter-relação de rinite alérgica com asma. Além dela, fatores genéticos e a hiper-responsividade das vias aéreas são outros determinantes dessa associação. Por exemplo, adultos com história familiar de asma e rinite apresentam um risco três a quatro vezes maior de desenvolver asma, e duas a seis vezes maior de desenvolver rinite do que adultos sem esses antecedentes ${ }^{9-11}$. Igualmente, a idade de início da atopia parece ser um fator determinante de rinite ou asma, já que sua aquisição antes de seis anos de idade foi considerada um fator preditivo positivo importante para persistência de asma, enquanto a atopia adquirida mais tardiamente esteve associada à rinite alérgica sazonal ${ }^{12}$.

Dentre os fatores ambientais, a poluição e o tabagismo aumentam significativamente o risco de asma e rinite. $\mathrm{O}$ tabagismo, por exemplo, é mais freqüentemente observado em adolescentes com asma e rinite do que em adolescentes sem asma e sem rinite, associação que também se observa em fumantes passivos ${ }^{13}$. Outros determinantes potenciais, que ainda requerem comprovação, estão listados na Tabela $1^{14}$.

Tabela 1 - Inter-relações da asma com rinite: determinantes e fatores de risco

\begin{tabular}{lc}
\hline Determinantes e fatores de risco & Evidências \\
\hline Relacionados com o paciente & \\
Fatores genéticos & + \\
História familiar de alergia & + \\
Atopia & + \\
Hiper-responsividade brônquica & - \\
Fatores imunológicos & + \\
& \\
Relacionados com o ambiente & \\
Tabagismo ativo e poluição & + \\
Tabagismo passivo & + \\
Ar frio & - \\
Umidade & - \\
Variações sazonais & - \\
Nutrição & - \\
Hábitos de vida & - \\
Condições socioeconômicas & - \\
Infecções & - \\
\hline
\end{tabular}

(+) existem evidências diretas ou indiretas

(-) não existem evidências diretas ou indiretas

\section{Aspectos morfológicos e fisiológicos}

O trato respiratório pode ser visto como uma unidade morfofuncional. A mucosa nasal e brônquica tem arquitetura semelhante, caracterizada por epitélio pseudo-estratificado, com células ciliadas colunares apoiadas sobre a membrana basal. Em praticamente toda a sua extensão, a mucosa do trato respiratório é rica em mastócitos e tecido linfóide, constituindo o chamado "tecido linfóide associa- do à mucosa ou ao brônquio". Na submucosa, encontramse vasos sanguíneos, glândulas mucosas, nervos e células inflamatórias, a saber, monócitos, linfócitos, mastócitos e eosinófilos.

Paralelamente a essas características comuns, existem diferenças. O nariz, além de ser um compartimento rígido, apresenta uma ampla rede vascular composta por ramos das artérias nasal lateral posterior e nasosseptal, por ramos da artéria oftálmica e por capilares subepiteliais. Esta rica vascularização é a origem da obstrução nasal, manifestação primordial nos processos inflamatórios do nariz. A via aérea inferior caracteriza-se pela sua plasticidade e pela presença de músculo liso da traquéia aos bronquíolos, o que explica a broncoconstrição que ocorre no asmático.

A inervação da mucosa nasal se faz por fibras adrenérgicas, colinérgicas e, finalmente, sem que ainda tenha sido claramente definida sua função, por fibras não adrenérgicas não colinérgicas. Neurotransmissores e neuropeptídeos (esses últimos, também identificáveis no tecido bronquial) do sistema nervoso autônomo são responsáveis pelo controle da homeostase, isto é, regulam a permeabilidade vascular e os processos secretórios. A inervação colinérgica é a principal via efetora da broncoconstrição. O controle adrenérgico se faz no nariz e nos brônquios, por mecanismos diferentes; os agonistas a-adrenérgicos são potentes vasoconstritores nasais, enquanto que os $\mathbf{B 2}$-adrenérgicos são potentes broncodilatadores.

Vários mecanismos foram propostos para explicar como a rinite alérgica não controlada atuaria como fator provocativo e agravante de asma ${ }^{1}$, a saber:

- reflexo nasobronquial: as evidências para sua existência ainda são paradoxais, pois argumentos em favor desta hipótese advêm de experiências em modelos animais, em que o uso de atropina inibiu a hiper-responsividade brônquica após provocação nasal; contraria esta hipótese a observação de que a aplicação de lidocaína tópica nasal não alterou o grau de reatividade brônquica;

- em caso de obstrução nasal - fato corriqueiro na rinite alérgica - há deficiências no aquecimento e umidificação do ar inspirado e ainda na função filtrante nasal. A respiração oral a ela secundária permite que os aeroalérgenos atinjam as vias aéreas inferiores, provocando hiper-responsividade brônquica e asma induzida pelo exercício;

- mediadores inflamatórios produzidos no nariz alcançariam o trato respiratório inferior por via sistêmica e/ou através de aspiração de secreções nasofaríngeas, provocando contração da musculatura lisa, ou induzindo processo inflamatório nas vias aéreas inferiores, mas, por outro lado, a aspiração é de ocorrência difícil e mesmo impossível em indivíduos hígidos;

- ativação da medula óssea e produção dos precursores das células inflamatórias após estímulo da mucosa nasal; 
- infecções virais de vias aéreas superiores contribuem para elevar o grau de hiper-responsividade e inflamação brônquica em asmáticos;

- discute-se, ainda, o papel hipotético desempenhado pelo óxido nítrico (NO). É produzido em larga escala pelo nariz e é um importante mediador no reflexo nasonasal, levando à vasodilatação e, por conseguinte, melhorando a vascularização pulmonar e a oxigenação.

\section{Evidências imunológicas e fisiopatológicas}

Processos inflamatórios nasais, como é o caso da rinite alérgica, repercutem desfavoravelmente em pacientes asmáticos. Muito embora os testes de provocação nasal não acarretem broncoespasmo, eles são capazes de determinar hiper-responsividade brônquica. Contudo, éilustrativo constatar que, em pacientes asmáticos, um teste de provocação nasal pode ser positivo em crianças sem qualquer manifestação clínica de rinite ${ }^{15}$.

A inflamação tem um papel crítico na patogênese da asma e da rinite e, como já foi citado, alguns fatores desencadeantes da reação inflamatória local são comuns a ambas. Inicia-se após a exposição ao alérgeno, em toda mucosa respiratória, e induz tanto rinite quanto asma. Pode ser detectada mesmo na ausência de sintomatologia florida, sendo referida então como "inflamação persistente mínima” (IPM). A IPM está associada à expressão da molécula de adesão CD54 (ICAM-1), que é o principal receptor para $o$ rinovírus. Tanto na asma quanto na rinite observa-se o mesmo infiltrado celular, composto por eosinófilos, mastócitos, linfócitos $\mathrm{T}$ e células da linhagem monocítica ${ }^{12}$. As moléculas de adesão e os mediadores inflamatórios também são idênticos: histamina, leucotrienos cisteínicos, citocinas Th2, entre elas as interleucinas 4,5 e 13, além de GMC-SF e RANTES.

Embora o mecanismo imunológico seja semelhante, observam-se diferenças histopatológicas na mucosa nasal e brônquica. Na rinite alérgica, de um modo geral, a integridade do epitélio é preservada, ou há descamação de pequena monta e não se observa espessamento importante da membrana basal, ao contrário do que ocorre na asma. Quando asma e rinite coexistem, a descamação e a solução de continuidade do epitélio também é mais intensa nos brônquios do que no nariz. A intensidade da inflamação é variável em pacientes com asma persistente moderada e grave, sendo a inflamação eosinofílica mais pronunciada nas vias aéreas inferiores ${ }^{16}$. $\mathrm{Na}$ asma persistente leve, a inflamação nasal e a brônquica parecem ter a mesma intensidade $^{12}$. Um achado interessante é que a inflamação eosinofílica nasal ocorre em pacientes asmáticos sem sintomas nasais e ainda não foi revelada em outras doenças pulmonares $^{12}$. Inversamente, em pacientes atópicos ou com rinite, mas sem asma, a mucosa brônquica apresenta espessamento da membrana basal e moderada inflamação eosinofílica $^{12}$.
Embora existam diferenças imunopatológicas, as reações que ocorrem após a exposição antigênica são as mesmas para a asma e a rinite alérgica. Caracterizam-se por uma reação alérgica imediata, tipo I, e pela reação de fase tardia, tipo $\mathrm{IVa}_{2}$, a inflamação crônica do epitélio e da submucosa na classificação de Gell e Coombs. Estão envolvidas neste processo células epiteliais, células de Langerhans, células dendríticas e outras células apresentadoras de antígenos. A medula óssea participa ativamente na produção de células inflamatórias, eosinófilos, basófilos e mastócitos através do aumento do número de células precursoras, diante da provocação antigênica ${ }^{17}$. O envolvimento da medula óssea neste processo revela ainda o caráter sistêmico da asma e do binômio asma-rinite alérgica.

Ocorre também recrutamento e ativação de linfócitos $\mathrm{CD}^{+} \mathrm{Th} 2$ e de células efetoras, tais como, eosinófilos, basófilos e mastócitos, e aumenta a expressão de citocinas, especialmente IL-4 e IL-13, que atuam na produção local de IgE e têm inegável papel neste processo. A expressão de outras citocinas também está aumentada, como é o caso de GM-CSF, RANTES, IL-3 e da IL-5, que atua prolongando a meia-vida dos eosinófilos. A produção de mediadores inflamatórios pré-formados, como a histamina, triptase, quinases, e de proteases pós-formadas, como leucotrienos, prostraglandinas, fator de agregação plaquetária e de neurotransmissores, tem perfil semelhante nas vias aéreas superiores e inferiores, embora a ação de cada um deles no órgão-alvo pareça ter um caráter diferente.

A reação de fase tardia se desenvolve após a provocação antigênica, dependendo do grau de exposição e da sensibilidade individual. É responsável pela persistência da sintomatologia, sendo que o recrutamento das células inflamatórias diminui o limiar de resposta aos estímulos antigênicos, fazendo com que a exposição contínua a baixas concentrações de aeroalérgenos provoque inflamação persistente da mucosa nasal e/ou brônquica. Este amplo leque de evidências que trazem consigo as bases moleculares e celulares apontam consistentemente para a unicidade de respostas e de comportamento do trato respiratório na asma e na rinite alérgica.

\section{Testes de provocação alérgica}

Os indícios mais promissores referentes às inter-relações rinite alérgica-asma provêm das informações fornecidas pelos estudos que se serviram dos testes de naso e broncoprovocação com alérgenos. Na sua essência, esses trabalhos alertam para o fato de que as reações alérgicas que têm lugar no nariz e nos brônquios são a tradução dos mesmos mecanismos imunoalérgicos, tanto no plano citológico como no plano humoral ${ }^{1,7}$.

Esses testes podem ser classificados em naturais ou observacionais, pois que resultam de registros que se seguem à exposição espontânea aos pólens; e em experimentais, estes últimos provocados em laboratório, seja por via nasal ou brônquica. 
Chakir et al., por exemplo, estudaram oito indivíduos antes e durante a estação polínica, todos eles com manifesta alergia a pólens, porém não eram asmáticos e nem possuíam evidências de hiper-responsividade brônquica. Durante a polinização, verificou-se uma reatividade brônquica aumentada, pois as biópsias de tecido bronquial revelaram uma elevação de linfócitos CD4+, CD8+ e CD45RO+, de células EG1 e de interleucina 5+. Observou-se, ainda, degranulação de eosinófilos, mas não dos mastócitos, razão pela qual esses indivíduos estavam indenes de manifestações asmáticas típicas. Ademais, os autores lograram identificar remodelamento brônquico moderado nos pacientes com rinite alérgica, mas sem asma, e postularam que a inflamação brônquica predisporia à asma ${ }^{18}$.

Numa perspectiva semelhante, Braunstahl et al. estudaram igualmente outros oito pacientes com rinite alérgica a gramíneas, porém sem asma ou hiper-responsividade brônquica, dos quais foram obtidos espécimes de biópsias nasais e brônquicas antes e após testes de broncoprovocação segmentar. Após a estimulação alergênica, os autores constataram infiltração eosinofílica, que se estendeu, inclusive, a outros segmentos, obstrução brônquica e alterações clínicas. Paralela e similarmente, na mucosa nasal foi observado um aumento da infiltração eosinofílica, de eotaxina e de interleucina 5 que, por sua vez e concomitantemente com a GM-CSF, também foram detectadas em maiores concentrações no sangue periférico. Ademais, houve expressiva correlação entre os escores clínicos nasais e brônquicos. Tais resultados sugerem tanto uma ativação sistêmica dos eosinófilos quanto a sua migração ao longo da mucosa do trato respiratório superior e inferior ${ }^{19}$.

Um ano depois, o grupo liderado por Braunstahl mostrou que, naqueles mesmos pacientes, o teste de broncoprovocação desencadeou, no sangue periférico, uma diminuição dos basófilos circulantes e aumento de interleucina 5, ao passo que, nas vias aéreas inferiores, ocorreu aumento de basófilos. No nariz, por outro lado, verificou-se degranulação de mastócitos e aumento de basófilos, supostamente oriundos do sangue periférico. Como a dose de alérgenos utilizada no experimento foi superior àquela encontrada em condições usuais de exposição, é pouco provável que estes mesmos alérgenos tenham perpassado a mucosa brônquica. Admite-se como hipótese mais plausível que a reação inflamatória local se acompanhe de uma outra envolvendo o conjunto das vias aéreas, reação esta que seria facilitada pelo transporte de células e mediadores pela via sanguínea, vale dizer, por um fenômeno de caráter sistêmico ${ }^{20}$.

Finalmente, um teste de provocação alérgica nasal induz eosinofilia tanto no nariz como nos brônquios, que tem correlação direta com a expressão de mediadores inflamatórios, entre os quais ICAM-1, VCAM-1 e selectina-E. Hipotetiza-se então que a absorção de mediadores próinflamatórios, a partir do local da provocação alérgica, promova uma liberação de eosinófilos medulares e, por via sanguínea, estas células alcançariam as mucosas nasal e brônquica, graças ao aumento da expressão de moléculas de adesão pelo endotélio vascular ${ }^{21}$.

\section{Evidências clínicas}

Evidências terapêuticas indiretas das inter-relações entre a rinite alérgica e a asma foram proporcionadas por estudos realizados nos últimos dez anos, nos quais, basicamente, foram empregados corticóides tópicos, anti-histamínicos, associados ou não a drogas simpaticomiméticas, e a associação de antileucotrienos com anti-histamínicos. Vários estudos demonstraram que, em pacientes asmáticos, os corticóides intranasais reduzem a hiper-responsividade brônquica pré-existente, provocada em ambiente laboratorial pela inalação de metacolina ou carbacol ${ }^{10,11,22,23}$. Além disso, em estudo retrospectivo, Adams et al. documentaram ser o tratamento com corticosteróide intranasal um fator de proteção para asma de maior gravidade ${ }^{24}$.

De forma complementar, verificou-se que a associação de loratadina - que, como um anti-histamínico, não é por si só eficaz na asma - à pseudoefedrina, droga que atua nos receptores alfa-adrenérgicos nasais, produziu melhora clínica e funcional e reduziu o consumo de beta-agonistas em pacientes com rinite alérgica e asma persistente moderada. Este efeito sinérgico também foi observado agregando-se anti-histamínicos a antileucotrienos ${ }^{25,26}$. Outro reforço a essas evidências indiretas foi proporcionado pelo estudo conhecido pela sigla ETAC (Early Treatment of Atopic Child), que envolveu um expressivo número de crianças, cujos resultados animadores indicaram que o uso contínuo de anti-histamínicos foi capaz de reduzir o surgimento subseqüente de asma ${ }^{27}$.

Finalmente, em estudo realizado com 3.500 pacientes de 12 a 60 anos de idade, $20 \%$ dos quais adolescentes, todos eles com rinite alérgica e asma, verificou-se que o risco de hospitalização, ou de visitas a pronto-socorro por asma aguda foi $50 \%$ menor no grupo de pacientes que recebia tratamento simultâneo para as duas afecções, quando comparados com o grupo não tratado ${ }^{28}$.

\section{Comentários finais}

$\mathrm{O}$ conceito de unicidade das vias aéreas em pacientes com rinite alérgica e asma é uma realidade, e o comprometimento da qualidade de vida determinado pela rinite, amplamente reconhecido. Apesar da necessidade da incorporação de novos conhecimentos que ratifiquem esta comorbidade e suas conseqüências para pacientes e suas famílias, há consenso na literatura de que o tratamento deve contemplar ambas as afecções. Mesmo que seja indispensável levar em consideração as diferenças entre as mucosas nasal e brônquica (rico sistema vascular nasal e musculatura lisa bronquial), é amplamente reconhecida a eficácia dos corticóides nasais e inalatórios nessas condições. Contudo, devido às limitações do emprego destas drogas em crianças, são necessários estudos controlados que, baseados no paradigma da unicidade das vias aéreas, avaliem esquemas terapêuticos que reúnam vantajosas relações risco-benefício e custo-efetividade. Ademais, ensaios clínicos que venham avaliar a eficácia de drogas com ação sistêmica, como é o caso dos antileucotrienos, propiciarão informa- 
ções úteis sobre sua eficácia comparativa com esteróides tópicos associados ou não a anti-histamínicos. É oportuno constatar que a imunoterapia específica possa, pelo menos nos casos de rinite alérgica, auxiliar na redução da hiperresponsividade brônquica inespecífica, ou até mesmo abortar o aparecimento de asma no decorrer da vida ${ }^{29-32}$.

Quando os recursos financeiros e materiais são limitados, realidade vivida pelo Brasil e por outros países em desenvolvimento, o tratamento farmacológico ocupa lugar de destaque. Os anti-histamínicos são reconhecidamente eficazes na rinite alérgica e, dependendo da intensidade dos sintomas e gravidade do quadro clínico, é recomendável substituí-los, ou a eles associar corticóides tópicos como, por exemplo, beclometasona. Entretanto, em casos onde há coexistência de rinite e asma, o tratamento desta última constitui-se numa prioridade clínica ${ }^{1}$.

\section{Referências bibliográficas}

1. Bousquet J, van Cauwenberge P, Khaltaev N. Allergic rhinitis and its impact on asthma. J Allergy Clin Immunol 2001;108 Suppl 5:147-334.

2. Grossman J. One airway, one disease. Chest 1997;111:11S-16S.

3. Passalacqua G, Ciprandi G, Canonica WC. The nose-lung interaction in allergic rhinitis and asthma: united airways disease. Curr Opin Allergy Clin Immunol 2001;1(1):7-13.

4. Canonica G. Special presentation. Eur Respir Mon 2001;18:b-d.

5. Simons FER. Allergic rhinobronchitis: the asthma-allergic rhinitis link. J Allergy Clin Immunol 1999;104:534-40.

6. Annesi-Maesano I. Rhinitis and asthma. Epidemiologic evidence. ACI International 2001;13:147-53.

7. Windom $\mathrm{HH}$, Togias A. Rhinitis and asthma: manifestations of one disease. ACI International 2001;13:154-61.

8. Bucca C. Are asthma-like symptoms due to bronchial or extrathoracic airway dysfunction? Lancet 1995;346:791-5.

9. Henriksen JM, Wenzel A. Effect of intranasally administered corticosteroid (budesonide) on nasal obstruction, mouth breathing, and asthma. Am Rev Respir Dis 1984;130:1014-8.

10. Corren J, Adinoff AD, Buchmeier AD, Irvin CG. Nasal beclomethasone prevents the seasonal increase in bronchial responsiveness in patients with allergic rhinitis and asthma. $\mathrm{J}$ Allergy Clin Immunol 1992;90:250-6.

11. Watson WTA, Becker AB, Simons FER. Treatment of allergic rhinitis with intranasal corticosteroids in patients with mild asthma: effect on lower airway responsiveness. J Allergy Clin Immunol 1993;91:97-101.

12. Vignola AM, Bresciani M, Demoly P, Chanez P, Bousquet J. Allergic inflammation of upper and lower airways: a continuum of disease? Eur Respir Rev 2001;11:152-6.

13. Worldwide variations in prevalence of symptoms of allergic rhinoconjunctivitis in children: the International Study of Asthma and Allergies in Childhood (ISAAC). Pediatr Allergy Immunol 1997;8:161-76.

14. Annesi-Maesano I. Epidemiological evidence of the occurrence of rhinitis and sinusitis in asthmatics. Allergy 1999;54 Suppl 57:7-13.

15. Jean R, Rufin P, Rufin A, Landais P, Waernssyckle S, de Blic J, Scheinmannn P. Diagnostic value of nasal provocation challenge with allergens in children. Allergy 1998;53:990-4.

16. Chanez P, Vignola AM, Vic P, Guddo F, Bonsignore G, Godard P, et al. Comparison between nasal and bronchial inflammation in asthmatic and control subjects. Am J Respir Crit Care Med 1999;159:588-95.
17. Denburg J. The nose, the lung and the bone marrow in allergic inflammation. Allergy 1999;54:124-31.

18. Chakir J, Laviolette M, Turcotte H, Boutet M, Boulet LP. Cytokine expression in the lower airways of nonasthmatic subjects with allergic rhinitis: influence of natural allergen exposure. J Allergy Clin Immunol 2000;106:904-10.

19. Braunstahl GF, Kleinjan A, Overbeek SE, Prins JB, Hoogsteden HC. Segmental bronchial provocation induces nasal inflammation in allergic rhinitis patients. Am J Respir Crit Care Med 2000;161:2051-7.

20. Braunstahl GJ, Overbeek SE, Fokkens WJ, Kleijan A, McEuen AR, Walls AF, et al. Segmental bronchoprovocation in allergic rhinitis patients affects mast cell and basophil numbers in nasal and bronchial mucosa. Am J Respir Crit Care Med 2001; 164:858-65.

21. Braunstahl GJ, Overbeek SE, Kleinjan A, Prins JB, Hoogsteden HC, Fokkens WJ. Nasal allergen provocation induces adhesion molecules expression and tissue eosinophilia in upper and lower airways. J Allergy Clin Immunol 2001;107:469-76.

22. Foresi A, Pelucchi A, Gherson G. Once daily intranasal fluticasone propionate (200 micrograms) reduces nasal symptoms and inflammation but also attenuates the increase in bronchial responsiveness during the pollen season in allergic rhinitis. J Allergy Clin Immunol 1996;98:274-82.

23. Aubier M, Levy J, Clerici C. Different effects of nasal and bronchial glucocorticosteroids administration on bronchial responsiveness in patients with rhinitis. Am Rev Respir Dis 1992;146:122-6.

24. Adams RJ, Fuhlbrigge AL, Finkelstein JA, Weiss ST. Intranasal steroids and the risk of emergency department visits for asthma. J Allergy Clin Immunol 2002;109:636-42.

25. Roquet A, Dahlen B, Kumlin M. Combined antagonism of leukotriene and histamine produces a predominant inhibition of allergen-induced early and late phase airway obstruction in asthmatics. Am J Respir Crit Care Med 1997;155:1856-63.

26. Meltzer EO, Malmstrom K, Lu S. Concomitant montelukast and loratadine as treatment for seazonal allergic rhinitis: a randomized placebo controlled clinical trial. J Allergy Clin Immunol 2000;105:917-22.

27. ETAC Study Group. Allergic factors associated with the development of asthma and the influence of cetirizine in a doublé blind randomized placebo controlled trial. Pediatr Allergy 1999;54:358-65.

28. Crystal-Peters J, Neslusan C, Crown WH, Torres A. Treating allergic rhinitis in patients with comorbid asthma: the risk of asthma-related hospitalizations and emergency department visits. J Allergy Clin Immunol 2002;109:57-62.

29. Grembiale RD, Camporota L, Naty S, Tranfa CME, Djukanovic R, Marsico SA. Effects of specific immunotherapy in allergic rhinitic individuals with bronchial hyperresponsiveness. Am J Respir Crit Care Med 2000;162:2048-52.

30. Moller C, Dreborg S, Ferdousi HA, Halken S, Host A, Jacobsen L, et al. Pollen immunotherapy reduces the development of asthma in children with seasonal rhinoconjonctivitis (the PAT Study). J Allergy Clin Immunol 2002;109:251-6.

31. Togias A. Systemic cross-talk between the lung and the nose. Am J Respir Crit Care Med 2001;164:726-7.

32. Ciprandi G, Canonica WG, Grosclaude M, Ostinelli J,Brazzola GG, Bousquet J. Effects of budesonide and fluticasone propionate in a placebo-controlled study on symptoms and quality of life in seasonal allergic rhinitis. Allergy 2002;57:586-91.

Endereço para correspondência:

Dr. Paulo Camargos

Departamento de Pediatria - Fac. de Medicina - UFMG

Avenida Alfredo Balena, 190 - sala 4061

CEP 30130-100 - Belo Horizonte, MG

Fone: (31) 3248.9773 - Fax: (31) 3248.9664

E-mail: pcamargs@ medicina.ufmg.br 